\title{
Pituitary Adenylate Cyclase-Activating Polypeptide Stimulates Glial Fibrillary Acidic Protein Gene Expression in Cortical Precursor Cells by Activating Ras and Rap1
}

\author{
Isabel Lastres-Becker*¹, Antonio Fernández-Pérez*, Beatriz Cebolla and Mario \\ Vallejo \\ Instituto de Investigaciones Biomédicas "Alberto Sols", Consejo Superior de \\ Investigaciones Científicas /Universidad Autónoma de Madrid, Spain.
}

Present address: ${ }^{1}$ Molecular Neurogenetics Section, Department of Neurology, JW Goethe University Medical School, Frankfurt am Main, Germany; ${ }^{2}$ Health Consumer Powerhouse, Rue Fossé au Loups 34, Brussels, Belgium.

*These authors contributed equally.

Address correspondence to:

Mario Vallejo, M.D., Ph.D.

Instituto de Investigaciones Biomedicas "Alberto Sols"

Calle Arturo Duperier 4, 28029 Madrid, Spain

Tel.: 91-585 4480

Fax: 91-585 4401

Email: mvallejo@iib.uam.es 


\begin{abstract}
Pituitary adenylate cyclase-activating polypeptide (PACAP) acts on cortical precursor cells to trigger glial fibrillary acidic protein (GFAP) gene expression and astrocyte differentiation by stimulation of intracellular cAMP production. Here, we show that as expected, PACAP activates cAMP-dependent protein kinase A. However, inhibition of protein kinase A does not prevent PACAP-induced GFAP gene expression or astrocytogenesis. PACAP also activates the small GTPases Rap1 and Ras, but either activation of Rap1 alone by selective stimulation of the guanine nucleotide exchange factor Epac, or expression of a constitutively active form of Ras, do not induce GFAP gene expression. Ras is activated by PACAP in a cAMP-dependent manner, and inhibition of Ras and/or Rap1 decreases PACAP-induced GFAP promoter stimulation. Thus, cAMP-dependent PACAP-induced GFAP expression during astrocytogenesis involves the coordinated activation of both Ras and Rap1, but activation of either one of them in isolation is not sufficient to trigger this response.
\end{abstract}




\section{INTRODUCTION}

During development of the central nervous system, the sequential generation of the different cell types destined to populate the adult brain depends, in part, on the type of extracellular signals to which neural precursors are exposed (Sauvageot and Stiles, 2002). Cortical astrocytes differentiate from progenitor cells exposed to cytokines of the interleukin-6 family, such as ciliary neurotrophic factor (CNTF), leukemia inhibitory factor (LIF) or cardiotrophin-1, or to bone morphogenetic proteins (BMP) (BarnabéHeider et al., 2005; Bonni et al., 1997; Gross et al., 1996; Ochiai et al., 2001; Rajan and McKay, 1998). The physiologic relevance of these findings is supported by studies showing that genetically engineered mice lacking one of the neurotrophic cytokines or their receptors exhibit a reduced number of astrocytes (Barnabé-Heider et al., 2005; Bugga et al., 1998; Koblar et al., 1998; Nakashima et al., 1999a), whereas the opposite is observed in the brains of mice overexpressing BMP (Gomes et al., 2003). Intracellular signaling systems triggered by neurotrophic cytokines and BMP, leading to the stimulation of GFAP gene transcription in differentiating astrocytes, involve the activation of STAT and Smad proteins, respectively (Bonni et al., 1997; He et al., 2005; Nakashima et al., 1999b; Rajan and McKay, 1998).

Previous studies carried out in our laboratory indicate that pituitary adenylate cyclase-activating polypeptide (PACAP), a member of the vasoactive intestinal peptide (VIP)/secretin/glucagon family, provides an additional signal for the generation of astrocytes from neural precursor cells (Cebolla and Vallejo, 2006; Vallejo and Vallejo, 2002). PACAP promotes astrocyte differentiation by acting on specific PAC1 receptors present in cortical precursor cells. These receptors use the cAMP-dependent pathway as a major intracellular signaling mechanism of peptide activation (Spengler et al., 1993), and therefore exposure of cortical precursor cells to PACAP results in increased 
intracellular levels of cAMP (Vallejo and Vallejo, 2002). In addition, we found that the cAMP analog $8 \mathrm{Br}-\mathrm{cAMP}$ is able to trigger astrocyte differentiation from cortical precursors (McManus et al., 1999), and that the astrocytogenic effect of PACAP can be blocked by a specific cAMP antagonist (Vallejo and Vallejo, 2002), thus supporting the notion that PACAP induces cortical precursor cell differentiation into astrocytes by activating a cAMP-dependent signaling pathway. However, the mechanisms by which cAMP triggers this response remain unknown.

It is known that cAMP can activate at least three different signaling pathways within cells. The first one to be characterized and the most extensively studied relies on the activation of protein kinase A (PKA), which then phosphorylates different substrates, including transcription factors such as CREB. Independently, cAMP can stimulate the guanine nucleotide exchange protein Epac (also known as cAMP-GEF), which then activates the GTPase Rap-1 (Bos, 2003). Finally, a third pathway has been identified in which the cAMP effector is another guanine nucleotide exchange protein called CNrasGEF, which activates Ras directly (Pham et al., 2000). In the present study, we have sought to determine the relative contributions of each one of these pathways to the stimulation of GFAP gene transcription during the astrocytogenic effect of PACAP in cortical precursor cells.

\section{RESULTS}

Astrocyte differentiation and stimulation of GFAP gene expression by PACAP do not require protein kinase A activity. We have previously determined that treatment of primary cortical precursor cells obtained from the brains of rat fetuses of 17 days of gestational age (E17) with PACAP or with the cAMP analog 8Br-cAMP results in astrocyte differentiation and stimulates GFAP expression (Cebolla and Vallejo, 2006; 
McManus et al., 1999; Vallejo and Vallejo, 2002). To confirm those findings we carried out immunofluorescence experiments and determined that fetal primary cortical cells proliferating in the presence of basic fibroblast growth factor (bFGF) express the neural precursor marker nestin, but not the glial markers GFAP or S100 $\beta$, nor the neuronal marker Tuj1 (Fig. 1A). When cells were treated with PACAP, nestin expression was downregulated and expression of the astroglial markers GFAP and S100 $\beta$ was induced (Fig. 1B). Exposure to PACAP did not induce expression of Tuj1 (Fig. 1B). However, when cells were treated with BDNF instead of PACAP, nestin expression was downregulated and Tuj1 expression was induced (Fig. 1C). Since coexpression of GFAP and S100 $\beta$ is a feature of mature astrocytes (Raponi et al, 2007), these results confirm our previous data and show that PACAP induces astrocyte differentiation from cortical precursor cells prepared from the brains of rat fetuses.

To monitor transcriptional responses of the GFAP gene promoter triggered by PACAP or 8Br-cAMP, we used transient transfections with GFAP-A7Luc, a GFAPluciferase reporter plasmid that we have previously used to identify and characterize promoter elements in the GFAP gene (Cebolla and Vallejo, 2006). We found that the luciferase activity elicited by PACAP is mimicked by 8Br-cAMP (Fig. 2A), supporting the notion that cAMP production by PACAP is sufficient to stimulate transcription from the GFAP promoter. Thus, we initially asked whether activation of PKA is required for PACAP-induced transcriptional transactivation of the GFAP promoter. To this end, we carried out transfections in primary cortical cells that had been pretreated with the PKAspecific inhibitor H89. We found that H89 does not inhibit luciferase activity in response to treatment of cells with PACAP (Fig. 2B).

Although cAMP is synthesized in cells upon activation of PACAP receptors, it is known that PACAP can induce the activation of different intracellular signaling systems 
(Grimaldi and Cavalaro, 1999; Lu et al., 1998; Nicot and DiCicco-Bloom, 2001; Spengler et al., 1993; Vallejo and Vallejo, 2002). Therefore, in view of these results, we considered the possibility that PKA is not activated in neural precursor cells exposed to PACAP. However, we ruled out this possibility, because we observed that treatment of cells with PACAP readily resulted in the phosphorylation of CREB (Fig. 2C), a well known target of PKA, and this phosphorylation was inhibited by pretreatment with H89 (Fig. 2D).

We found also that pretreatment with $\mathrm{H} 89$ did not prevent stimulation of endogenous GFAP expression (Fig. 2E) and did not block astrocyte differentiation elicited by PACAP in primary cortical precursor cells (Fig. 2F). Thus, we conclude from these experiments that exposure of cortical precursor cells to PACAP results in activation of PKA, but PKA is not involved in the transcriptional transactivation of the GFAP promoter during astrocyte differentiation.

Since cAMP activity is required for astrocyte differentiation induced by PACAP (Vallejo and Vallejo, 2002), we argued that cAMP could activate additional signaling pathways different from PKA, and we turned our attention to investigate the possible involvement of the Epac-Rap1 and/or the CNrasGEF/Ras pathways.

Involvement of Epac-Rap1. To investigate whether PACAP-induced GFAP gene expression could be due to the specific activation of Epac-Rap1, we first determined whether treatment of primary cortical precursors with PACAP results in activation of Rap1. Activated Rap1 (Rap1-GTP) was assayed using a glutathione S-transferase (GST) pull-down assay with a fusion protein composed of GST and the Rap1 binding domain of RalGDS (GST-RalGDS-RBD), which specifically binds the active, GTP-bound form of Rap1, followed by western immunoblotting with a Rap1-specific antibody (de Rooij 
and Bos, 1997; Zwartkruis et al., 1998). We observed that treatment of primary cortical precursor cells with PACAP results in the activation of Rap1. The onset of this response is relatively slow, reaching maximum levels 15 min after exposure of cells to PACAP, and persisting for at least 30 minutes (Fig. 3A). As a positive control, we observed that Rap1 is activated by exposure for 15 minutes to 8CPT-2-O-Me-cAMP (Fig. 3A), a cAMP analog that is a selective activator of Epac (Enserink et al., 2002).

In addition, we tested whether the blockade of the PACAP-induced activation of the Epac-Rap1 pathway would affect the stimulation of GFAP promoter activity. For this purpose, we cotransfected primary cortical precursor cells with the reporter plasmid GFAP-A7Luc and an expression vector encoding Rap1N17, a dominant negative mutant of the Epac effector Rap1 (Vossler et al., 1997). We observed that in the presence of increasing amounts of Rap1N17, the stimulatory effect of PACAP on GFAP promoter activity decreased (Fig. 3B). In contrast, Rap1N17 did not prevent the stimulation of the GFAP promoter induced by CNTF (Fig. 3C), supporting the notion that the effect of Rap1N17 is not due to toxicity and that the induction of GFAP promoter activity by PACAP in neural precursors involves the specific activation of the Epac-Rap1 pathway.

Based on these results, it could be expected that stimulation of Epac in cortical precursor cells should trigger astrocyte differentiation and induce GFAP expression by stimulating transcriptional activity of the GFAP promoter. To test this notion, we transfected primary cortical precursors with the reporter plasmid GFAP-A7Luc, and treated them with the Epac-specific agonist 8CPT-2-O-Me-cAMP. We found that this treatment did not increase basal luciferase activity, indicating that this compound is not able to mimic the activity of PACAP or $8 \mathrm{Br}$-cAMP on the GFAP promoter (Fig. 4A). In addition, in contrast with what we observed in the case of PACAP or 8Br-cAMP, 
exposure of primary cortical precursor cells to 8CPT-2-O-Me-cAMP did not induce endogenous GFAP expression or astrocyte differentiation, as assessed by western immunoblot and immunocytochemistry, respectively (Fig. 4B and C).

Taken together, these experiments suggest that activation of the Epac-Rap1 pathway is involved in the response to PACAP but it is not sufficient to stimulate GFAP promoter activity on its own. Since inhibition of intracellular signaling by a cAMPspecific antagonist blocks astrocyte differentiation induced by PACAP (Vallejo and Vallejo, 2002), we sought to investigate whether an additional cAMP-dependent pathway could be activated. For this reason, we studied the possible involvement of Ras, which can be activated via stimulation of the cAMP-dependent exchange factor CNrasGEF (Pham et al., 2000).

Involvement of Ras. To test whether PACAP can activate Ras in primary cortical precursor cells, we used a GST pull-down assay with a fusion protein composed of GST and the Ras-binding domain of Rafl (GST-Rafl-RBD), which specifically binds the active, GTP-bound form of Ras, followed by western immunoblotting with a Rasspecific antibody (Taylor and Shalloway, 1996). We found that PACAP transiently activates Ras within 5 minutes of treatment, and by 15 minutes the levels of GTP-bound Ras had practically returned to basal levels (Fig. 5A).

To test whether Ras activation is related to the effect of PACAP on GFAP gene expression, we cotransfected primary cortical precursor cells with GFAP-A7Luc and an expression vector encoding RasN17, a dominant negative mutant of Ras (Matallanas et al., 2003). Expression of RasN17 resulted in a marked, although incomplete inhibition of the luciferase activity induced by PACAP, but did not affect luciferase activity induced by CNTF (Fig. 5B and C), indicating that the effect of RasN17 is not due to 
toxicity. Thus, the activation of Ras on its own appears to be important for the stimulation of the GFAP gene promoter triggered by PACAP. Then, we sought to explore whether activation of Ras is sufficient to stimulate transcription from the GFAP promoter using RasV12, a constitutively active mutant of Ras (Delgado et al., 2000). We observed that cotransfections of primary cortical precursors with the GFAP-A7Luc reporter and with increasing amounts of an expression vector encoding RasV12 did not alter luciferase activity significantly (Fig. 5D), indicating that activation of Ras is not sufficient to stimulate GFAP gene expression.

Ras can be activated by cAMP via stimulation of the nucleotide exchange factor CNrasGEF (Pham et al., 2000). Because no cAMP analogs that act specifically and selectively as CNrasGEF agonists have been developed, we tested the involvement of cAMP on the PACAP-induced activation of Ras indirectly. We have observed previously that the ability of PACAP to induce astrocyte differentiation from primary cortical precursors can be mimicked by $8 \mathrm{Br}-\mathrm{cAMP}$, and can be blocked by the cAMP antagonist Rp-cAMPS (McManus et al., 1999; Vallejo and Vallejo, 2002). In agreement with these findings, we observed that pretreatment of cells with Rp-cAMPS inhibits the activation of Ras induced by PACAP (Fig. 6A). In addition, in transfected cells, stimulation of GFAP-A7Luc activity elicited by treatment of cells with 8Br-cAMP was reduced in the presence of the dominant negative inhibitor RasN17 (Fig. 6B).

The experiments carried out using either the Rap1 inhibitor Rap1N17 or the Ras inhibitor RasN17 show that inhibition of the transcriptional activity of the GFAP promoter stimulated by PACAP is not complete. Therefore, we tested the effects of the two negative dominant inhibitors together. In agreement with our previous results, PACAP-induced GFAP-A7Luc activity in transfected primary cortical precursor cells was reduced by about $40 \%$ in the presence of the Rap 1 inhibitor, and by almost $50 \%$ in 
the presence of the Ras inhibitor (Fig. 7A). When both inhibitors were present together, PACAP-, but not CNTF-induced GFAP promoter activity was inhibited by more than 80\% (Fig. 7A and B). In addition, we observed that knockdown of both Ras and Rap1 by RNA interference prevented the stimulation of endogenous GFAP expression induced by PACAP without affecting the stimulation induced by CNTF (Fig. 7C).

All of the above experiments indicate that activation of either Ras or Rap1 is not sufficient to stimulate the GFAP gene promoter, although both appear to be necessary for stimulation. This suggests that the expression of GFAP in neural precursor cells requires the coordinated activation of both signaling pathways. To test this notion, we cotransfected GFAP-A7Luc with the expression vector encoding RasV12 to stimulate the Ras-dependent pathway constitutively, and then treated the cells with 8CPT-2-OMe-cAMP to stimulate the Epac-Rap1-dependent pathway. These experiments showed that 8CPT-2-O-Me-cAMP only activated luciferase activity when was RasV12 present, even though RasV12 had no effect on its own (Fig. 7D). Therefore, these experiments indicate that GFAP promoter stimulation require the concomitant activation of both Epac-Rap1- and Ras-dependent signaling pathways.

\section{DISCUSSION}

Our previous work indicates that induction of astrocytogenesis and stimulation of GFAP gene expression by PACAP are due to activation of specific PAC1 type receptors expressed on cortical precursor cells and depend on the activation of signaling pathways that require cAMP (Vallejo and Vallejo, 2002). In the present study we show

that stimulation of GFAP gene expression by PACAP in cortical precursors is associated to activation of the small GTPases Rap1 and Ras. Interestingly, isolated stimulation of Epac-Rap1 with a specific cAMP analog or constitutive activation of Ras 
alone are not sufficient to activate transcription from the GFAP promoter. Instead, we found that this response requires the coordinated activation of both signaling pathways. This is not entirely surprising in view of the number and complexity of interactions that mediate crosstalk between the different cAMP-dependent signaling cascades within cells (Stork and Schmitt, 2002). In addition, our data are in agreement with the observed lack of effects of a constitutively active isoform of Rap1 expressed in differentiating astrocytes of transgenic mice on astrocyte differentiation (Apicelli et al., 2003).

We observed that the activation of Rap1 is delayed and it is apparently weaker relative to that of Ras. Thus, it could be possible that activation of Rap1 requires previous activation of Ras, as has been shown to be the case in different cell types (Li et al., 2006). However, it is unlikely that activation of Rap1 in cortical precursors depends entirely on activation of Ras, because partial GFAP promoter stimulation is still observed in the presence of the dominant negative inhibitor RasN17.

Activation of Rap1 and/or Ras by PACAP has been shown in different cell types, including neuronal cells and astrocytes (Bouschet et al., 2003; Dasgupta et al., 2003; Obara et al., 2007; Romano et al., 2003). In pituitary cells, PACAP-induced transactivation of the prolactin gene promoter is also accompanied of the activation of Rap1 and Ras (Romano et al., 2003). However, in this case the activations of these signaling pathways have antagonic effects: whereas Rap1 stimulates transcription, Ras inhibits prolactin gene promoter activity. In PC12 and in cerebellar granule cells stimulation of ERKs by PACAP requires that both Rap1 and Ras are activated (Bouschet et al., 2003; Obara et al., 2007). Interestingly, the activation of these small GTPases by PACAP in cerebellar cells requires the activation of PKA by cAMP (Obara et al., 2007). 
We found that PACAP is able to activate PKA in cortical precursor cells, and that this activation is responsible for phosphorylation of CREB. Studies carried out in pituitary cells indicate that PACAP, acting on PAC1-type receptors, induces transcription of the gonadotropin-releasing hormone receptor gene by stimulating promoter activity via phosphorylation of CREB by cAMP-dependent PKA (Pincas et al., 2001). However, in cortical precursor cells we found that the stimulation of promoter activity of the GFAP gene is independent of the activation of PKA, because PACAP induces GFAP expression and triggers astrocyte differentiation even in the presence of a PKA inhibitor. Since inhibition of either Rap1 or Ras results in decreased PACAP-induced GFAP promoter activity, it follows that PKA is not required for the activation of Rap1 or Ras in these cells. In addition, the observation that PKA activation and CREB phosphorylation do not participate in PACAP-induced GFAP gene expression is consistent with the observation that the region of the GFAP promoter that mediates cAMP-dependent transactivation does not contain any sequence corresponding to a typical cAMP-response element for binding of CREB-like proteins (BC and MV, unpublished). A detailed characterization of the GFAP promoter region that confers responsiveness to PACAP/cAMP has been carried out in our laboratory and will be reported elsewhere.

In mature astrocytes, PACAP/cAMP signaling leads to activation of Rap1, but as a consequence Ras is inhibited (Apicelli et al., 2003; Dasgupta et al., 2003; Dugan et al., 1999), in agreement with previous studies showing that inhibition of the Ras/Raf1 pathway by Rap1 is dependent on cAMP activation of PKA (Altschuler et al., 1995; Schmitt and Stork, 2001). In contrast, in glial progenitors we observed that both Rap1 and Ras are activated by PACAP. It is known that PACAP acts on PAC1 receptors expressed in cortical cells, but it exerts different actions depending on their 
developmental stage. Thus, before birth PACAP promotes neuronal differentiation from early neural precursors (Suh et al., 2001) and astrogliogenesis from late precursors (Nishimoto et al., 2007; Vallejo and Vallejo, 2002), whereas postanally, PACAP regulates the growth and differentiation of oligodendrocyte progenitors (Lee et al., 2001). Therefore the signaling mechanisms on which PACAP acts during cortical development appear to differ in different cell lineages and to be developmentally regulated. This developmental regulation could be due to the differential expression of effector proteins such as B-Raf, activated by Rap1, that is not expressed in mature astrocytes (Dugan et al., 1999). In addition, the generation of different PAC1 receptor splice variants in cortical precursors (Vallejo and Vallejo, 2002) could be responsible for the coupling to different signaling pathways.

It is known that astrocytes derive sequentially from the same precursor cells that first generate neurons (Barnabé-Heider et al., 2005; Miller and Gautier, 2007; Qian et al., 2000). We found that PACAP does not induce neuronal differentiation from E17 precursors, although earlier reports suggest that PACAP can induce neuronal differentiation from E13.5 precursor cells (Lu and DiCicco-Bloom, 1997). In turn, we have observed that PACAP is unable to induce astrocyte differentiation from E14 cortical precursors (our unpublished observations). The molecular mechanisms that may explain these differential effects of PACAP on cortical precursors are unknown. However, there is evidence for the existence of silencing mechanisms that prevent the inappropriate onset of astrocyte differentiation and GFAP expression before neurogenesis is completed even in the presence of astrogliogenic signals; and in turn, the acquisition of competence to generate astrocytes is accompanied by the coordinate inhibition of the neurogenic potential of precursor cells (Fan et al., 2005; Hermanson et 
al., 2002; Miller and Gautier, 2007; Nieto et al., 2001; Park et al., 1999; Qian et al., 1997; Song and Ghosh, 2004; Sun et al., 2001; Takizawa et al., 2001; Viti et al., 2003).

Our results show that the activation of Ras by PACAP in cortical precursor cells requires cAMP, because it can be efficiently blocked by the cAMP antagonist RpcAMPS. Furthermore, the activation of Ras by cAMP is also supported by our experiments showing that the transcriptional effects of $8 \mathrm{Br}$-cAMP on the GFAP promoter can be significantly reduced by the dominant negative mutant RasN17. It is unlikely that the inhibition of Ras activation by Rp-cAMPS is due to inhibition of PKA, because inhibition of PKA by H89 does not affect the response to PACAP in terms of GFAP promoter stimulation and astrocyte differentiation. Since the cAMP antagonist Rp-cAMPS can block the cAMP-dependent activation of small GTPases such as Epac in addition to blocking PKA (Rehmann et al., 2003; Van Haastert et al., 1984), it is possible that the effect of the cAMP antagonist on the activation of Ras by PACAP could be due to direct blockade of a Ras-associated GTPase such as CNrasGEF. This GTPase can activate Ras in a PKA-independent manner upon treatment with 8Br-cAMP (Amsen et al., 2006; Pham et al., 2000) or in response to elevation of intracellular cAMP levels following ligand-dependent stimulation of $\beta 1$ adrenergic receptors (Pak et al., 2002), which are seven transmembrane domain $G$ protein-coupled receptors similar to PAC1 receptors for PACAP.

The molecular mechanisms by which PACAP and cAMP stimulate transcription of the GFAP gene during astrocyte differentiation are unknown. Ongoing studies in our laboratory indicate that they may involve changes in the intracellular concentrations of calcium ions. In different cell types, activation of Ras or Epac can lead to changes in intracellular calcium concentrations (Fitzgerald, 2000; Kang et al., 2003; Ster et al., 2007). Thus, cAMP production following PACAP activation of PAC1 receptors in 
cortical precursor cells triggers the stimulation of Rap1- and Ras-dependent intracellular signaling cascades that could include changes in the concentrations of calcium ions. These changes would lead to stimulation of transcriptional activity of the GFAP gene during the process of astrocyte differentiation.

\section{EXPERIMENTAL METHODS}

Reagents. CNTF and bFGF were from PeproTech EC Ltd. (London, England). PACAP38, H-89, and 8-Br-cAMP were obtained from Sigma Chemical Co. (Madrid, Spain). 8CPT-2-O-Me-cAMP was purchased from Biolog Life Science Institute (Bremen, Germany).

Plasmids. The luciferase reporter plasmid GFAP-A7Luc bearing a region of the rat GFAP gene promoter corresponding to nucleotides -1546 to +13 relative to the transcription initiation site has been described in detail in previous studies (Bonni et al., 1997; Cebolla and Vallejo, 2006; Krohn et al., 1999). The plasmids pGEX-Raf1-RBD encoding GST-Raf1-RBD, and those encoding RasN17 and RasV12 were provided by Dr. P. Crespo (Universidad de Cantabria, Santander, Spain) and have been described (Matallanas et al., 2003). pGEX-RalGSD-RBD encoding GST-RalGSD-RBD and the expression vector for Rap1N17 (Vossler et al., 1997) were provided by Dr. L. Cacicedo (Hospital Ramon y Cajal, Madrid) with permission from Dr. P.J.S. Stork (Vollum Institute, Portland, Oregon).

Cell culture and transfections. Primary cortical cell cultures were prepared from the cerebral cortex dissected from fetal brains of E17 Wistar rats as described (Vallejo and Vallejo, 2002). Briefly, cell suspensions prepared by trituration of the fetal cortex were 
washed and resuspended in serum-free DMEM containing N1 supplement (Sigma) and $1 \mathrm{mM}$ sodium pyruvate (defined medium). Basic FGF $(20 \mathrm{ng} / \mathrm{ml})$ was added and cells were seeded into $10 \mathrm{~cm}$ dishes coated with poly-ornithine, at a density of $2-4 \times 10^{4}$ cells $/ \mathrm{cm}^{2}$. Cells were incubated for expansion at $37{ }^{\circ} \mathrm{C}$ for 3-4 days. Medium was replaced every two days.

Differentiation experiments were carried out with cells plated into $35 \mathrm{~mm}$ dishes at a density of $5 \times 10^{4}$ cells $/ \mathrm{cm}^{2}$. After incubation at $37{ }^{\circ} \mathrm{C}$ for 24 hours, bFGFcontaining medium was replaced with bFGF-free defined medium, and PACAP (100 $\mathrm{nM})$, 8CPT-2-O-Me-cAMP $(100 \mu \mathrm{M})$ or BDNF $(50 \mathrm{ng} / \mathrm{ml})$ were immediately added. After the addition of these compounds cells were incubated for 2-5 days, at the end of which they were processed for immunocytochemistry or immunofluorescence. To evaluate the possible involvement of PKA activation during astrocyte differentiation, exposure to PACAP was limited to two hours, since we have previously established that this period of time is sufficient to trigger differentiation (Vallejo and Vallejo, 2002). After this time the medium was replaced and cells were cultured in defined medium until harvesting. In this case, $\mathrm{H} 89(10 \mu \mathrm{M})$ was added 15 minutes before PACAP.

For transfections, $10^{6}$ cells/plate were seeded into poly-ornithine-coated $60 \mathrm{~mm}$ dishes. After an overnight incubation in defined medium in the presence of bFGF (20 $\mathrm{ng} / \mathrm{ml})$, the medium was removed and $3 \mu \mathrm{g}$ of reporter plasmid DNA mixed with $10 \mu \mathrm{l}$ FuGENE 6 Transfection Reagent (Roche) were added in $4 \mathrm{ml}$ defined medium and incubated for 4 hours. After this, the medium-DNA mix was removed and substituted with fresh defined medium, or with defined medium containing different compounds for treatments as indicated. In cotransfection experiments, expression vectors were added at the indicated amounts, and total DNA amount was kept constant by addition of empty vector. Luciferase activity and normalization of values were determined using a 
commercial assay system (Promega) 48 hours after transfection exactly as described (Cebolla and Vallejo, 2006). Transfection of RSV-Luc was used as an independent standard for normalization, and efficiencies were corrected by using the Renilla luciferase assay system (Promega). All the values are expressed as mean \pm s.e.m. of at least five independent experiments carried out in duplicates.

Western blot. Whole cell extracts from primary cells were prepared and proteins (20 $\mu \mathrm{g})$ were resolved by SDS-PAGE and transferred to a nitrocellulose membrane. GFAP and $\beta$-actin immunoreactivities were detected with specific monoclonal antibodies, (clone G-A-5, 1:10,000 dilution; and clone AC-15, 1:10,000 dilution, respectively; Sigma) followed by incubation with a horse anti-mouse peroxidase-conjugated secondary antibody (1:5,000 dilution) (BioRad, Hercules, CA). Rabbit polyclonal primary antisera were used for immunodetection of CREB (Santa Cruz, used at 1:2000 dilution) and phospho-CREB (Upstate, used at 1:1000 dilution). Incubations with these antisera were followed by incubation with a goat anti-rabbit peroxidase-conjugated secondary antibody (1:10,000 dilution) (BioRad, Hercules, CA). Immunoreactive bands were visualized using an enhanced chemiluminescence detection system (ECL, Amersham, Buckinghamshire, England).

Endogenous Rap1 and Ras activation assay. Activated Rap1 (Rap1-GTP) or activated Ras (Ras-GTP) were detected using glutathion-S-transferase (GST) pull down assays as described (de Rooij and Bos, 1997; Taylor and Shalloway, 1996; Zwartkruis et al., 1998). Cells were washed twice with ice-cold PBS and then they were incubated at $4{ }^{\circ} \mathrm{C}$ for $10 \mathrm{~min}$ in $0.5 \mathrm{ml}$ of lysis buffer containing: $25 \mathrm{mM}$ Tris- $\mathrm{HCl}(\mathrm{pH} 7.5), 5 \mathrm{mM}$ EGTA, $15 \mathrm{mM} \mathrm{NaCl}, 5 \mathrm{mM} \mathrm{MgCl}_{2}, 1 \%$ Triton $\mathrm{X}-100,1 \% \mathrm{~N}$-octilglucoside, $1 \mathrm{mM}$ 
phenylmethylsulfonyl fluoride and protease inhibitors (Complete Protease Inhibitor Cocktail, Roche). Lysates were clarified by centrifugation at $10,000 \mathrm{~g}$ for 10 minutes, and $1 \mathrm{mg}$ of total proteins from the supernatants were incubated with glutathionesepharose beads (Amersham Biosciences). The beads were freshly coupled to GSTRalGDS-RBD to isolate Rap1-GTP, or to GST-Raf1-RDB to isolate Ras-GTP. Protein complexes were allowed to form for $1 \mathrm{~h}$ at $4{ }^{\circ} \mathrm{C}$, after which the beads were washed three times with lysis buffer and resuspended in Laemmli's sample buffer. Denatured proteins were resolved by SDS-PAGE (12\%), transferred to nitrocellulose membranes, and detected by western immunoblot using an affinity purified rabbit polyclonal antiRap1 antiserum (Santa Cruz Biotechnology; 1:1000 dilution) or a mouse monoclonal anti-Ras antiserum (Oncogene Research Products, San Diego, California; 1:1000 dilution). Immunoreactive bands were visualized by enhanced chemiluminescence (ECL, Amersham, Buckinghamshire, England).

Immunocytochemistry and immunofluorescence. $\mathrm{DAB}$ immunocytochemistry for GFAP was carried out with cells plated into poly-ornithine-coated $35 \mathrm{~mm}$ tissue culture dishes, using a specific monoclonal antibody (1:500 dilution) (clone G-A-5, Sigma) exactly as described (Vallejo and Vallejo, 2002). Immunodetection was carried out using immunoperoxidase staining with a Vectastain ABC kit (Vector Laboratories).

For immunofluorescence, cells were grown on glass coverslips and fixed. Primary antibodies used were anti-GFAP monoclonal antibody (1:500 dilution, Sigma), anti-S100 $\beta$ monoclonal antibody (1:500 dilution, Sigma), rabbit polyclonal anti-Nestin antiserum (1:4000 dilution ) (McManus et al., 1999), and anti-Tuj1 monoclonal antibody (1:500 dilution, Sigma). In the case of double GFAP-S100 $\beta$ immunofluorescence, a rabbit polyclonal anti-GFAP antiserum (1:200 dilution, Dako) 
was used. Secondary antibodies were Alexa-488 or Alexa-546 donkey anti-rabbit or donkey anti-mouse (Molecular Probes) used at a 1:500 dilution. Nuclei were counterstained with Hoechst 3342 (Invitrogen). Digital images were taken using a Leica TCS SP5 confocal microscope, except those corresponding to experiments with BDNF, in which case a Nikon 90i microscope equipped with a digital camera was used.

RNA interference. RNA interference was carried out using double stranded RNA duplexes transfected into primary cortical cells from the cerebral cortex of E17 Wistar rats prepared as described above. Cells $\left(2 \times 10^{6}\right.$ per plate) cultured into $60 \mathrm{~mm}$ dishes were incubated in $1.5 \mathrm{ml}$ DMEM and transfected by adding a mixture containing $5 \mu \mathrm{l}$ Lipofectamine (Invitrogen), $500 \mu \mathrm{l}$ OptiMEM (Invitrogen) and small interfering RNA (siRNA). After incubation for 6 hours, the medium-siRNA mix was removed and substituted with fresh defined medium. Forty eight hours later, cells were treated with PACAP $(100 \mathrm{nM})$ or CNFT $(30 \mathrm{ng} / \mathrm{ml})$ for another 24 hours, after which GFAP expression was assayed by western immunoblot. The sequences of the custom siRNA duplexes (Stealth ${ }^{\mathrm{TM}}$ RNAi system, Invitrogen) used are as follows (only sense strand is indicated):

H-Ras, CCAAGUCCUUUGAAGACAUACAUCA;

K-Ras, GAAUAAGUGUGACUUGCCUUCUAGA;

N-Ras, UGGCCAAGAGUUAUGGAAUUCCAUU;

Rap1a, CAGAAUUUAGCAAGACAGUGGUGUA;

Rap1b, CAGCCAUGAGAGAUCUGUACAUGAA.

A commercially available Stealth ${ }^{\mathrm{TM}}$ RNAi negative control duplex with medium (48\%) GC content (Invitrogen) was used. Cells were transfected with a mixture of siRNAs for the three Ras isoforms, a mixture of siRNAs for the two Rap1 isoforms, or a mixture of 
siRNAs for all Ras and Rap1 isoforms. Each siRNA duplex was used at a concentration of $80 \mathrm{nM}$. The total concentration of siRNA (400 nM) was kept constant in all transfections by adding the negative control siRNA to the mixture as necessary. Transfection efficiency was assessed by a fluorescein-labeled siRNA (Invitrogen) and estimated to be greater than $90 \%$.

\section{ACKNOWLEDGEMENTS}

This work was funded by grants from the Community of Madrid (GR/SAL/0774/2004) and Spanish Ministry of Education and Science (BMC200200870 and BFU2005-02052). I.L-B. and B.C. were supported by fellowships from the Community of Madrid. A.F.P. was supported by a fellowship from the Spanish Ministry of Education and Science. We thank Piero Crespo, Philip Stork and Lucinda Cacicedo for plasmids.

\section{REFERENCES}

Altschuler, D.L., Peterson, S.N., Ostrowski, M.C., and Lapetina, E.G. (1995) Cyclic AMP-dependent activation of Rap1b. J. Biol. Chem. 270: 10373-10376.

Amsen, E.M., Pham, N., Pak, Y., and Rotin, D. (2006) The guanine nucleotide exchange factor CNrasGEF regulates melanogenesis and cell survival in melanoma cells. J. Biol. Chem. 281: 121-128.

Apicelli, A.J., Uhlmann, E.J., Baldwin, R.L., Dong, D., Nagy, A., Guha, A., and Gutman, D.H. (2003) Role of the Rap1 GTPase in astrocyte growth regulation. Glia 42: 225-234. 
Barnabé-Heider, F., Wasylnka, J.A., Fernandes, K.J.L., Porsche, C., Sendtner, M., Kaplan, D.R., and Miller, F.D. (2005) Evidence that embryonic neurons regulate the onset of cortical gliogenesis via cardiotrophin-1. Neuron 48: 253-265.

Bonni, A., Sun, Y., Nadal-Vicens, M., Bhatt, A., Frank, D.A., Rozovsky, I., Stahl, N., Yancopoulos, G.D., and Greenberg, M.E. (1997) Regulation of gliogenesis in the central nervous system by the JAK-STAT signaling pathway. Science 278: 477-483.

Bos, J.L. (2003) Epac: a new cAMP target and new avenues in cAMP research. Nature Rev. Mol. Cell Biol. 4: 733-738.

Bouschet, T., Perez, V., Fernandez, C., Bockaert, J., Eychene, A., and Journot, L. (2003) Stimulation of the ERK pathway by GTP-loaded Rap1 requires the concomitant activation of Ras, protein kinase $\mathrm{C}$, and protein kinase $\mathrm{A}$ in neuronal cells. J. Biol. Chem. 278: 4778-4785.

Bugga, L., Gadient, R.A., Kwan, K., Stewart, C.L., and Patterson, P.H. (1998) Analysis of neuronal and glial phenotypes in brains of mice deficient in leukemia inhibitory factor. J. Neurobiol. 36: 509-524.

Cebolla, B. and Vallejo, M. (2006) Nuclear factor-I regulates glial fibrillary acidic protein gene expression in astrocytes differentiated from cortical precursor cells. J. Neurochem. 97: 1057-1070.

Dasgupta, B., Dugan, L.L., and Gutmann, D.H. (2003) The neurofibromatosis 1 gene product neurofibromin regulates pituitary adenylate cyclase-activating polypeptide-mediated signaling in astrocytes. J. Neurosci. 23: 8948-8954.

de Rooij, J. and Bos, J.L. (1997) Minimal Ras-binding domain of Rafl can be used as an activation-specific probe for Ras. Oncogene 14: 623-625. 
Delgado, M.D., Vaque, J.P., Arozarena, I., Lopez-Ilasaca, M.A., Martinez, C., Crespo, P., and Leon, J. (2000) H-, K- and N-Ras inhibit myeloid leukemia cell proliferation by a p21WAF1-dependent mechanism. Oncogene 19: 783-790.

Dugan, L.L., Kim, J.S., Zhang, Y., Bart, R.D., Sun, Y., Holzman, D.M., and Gutmann, D.H. (1999) Differential effects of cAMP in neurons and astrocytes. Role of BRaf. J. Biol. Chem. 274: 25842-25848.

Enserink, J.M., Christensen, A.E., de Rooij, J., van Triest, M., Schwede, F., Genieser, H.G., Doskeland, S.O., Blank, J.L., and Bos, J.L. (2002) A novel Epac-specific cAMP analogue demonstrates independent regulation of Rap1 and ERK. Nat. Cell Biol. 4: 901-906.

Fan, G., Martinowich, K., Chin, M.H., He, F., Fouse, S.D., Hutnick, L., Hattori, D., Ge, W., Shen, Y., Wu, H., ten Hoeve, J., Shuai, K., and Sun, Y.E. (2005) DNA methylation controls the timing of astrogliogenesis through regulation of JAKSTAT signaling. Development 132: 3345-3356.

Fitzgerald, E.M. (2000) Regulation of voltage-dependent calcium channels in rat sensory neurones involves a Ras-mitogen-activated protein kinase pathway. $J$. Physiol. 527: 433-444.

Gomes, W.A., Mehler, M.F., and Kessler, J.A. (2003) Transgenic overexpression of BMP4 increases astroglial and decreases oligodendroglial lineage commitment. Dev. Biol. 255: 164-177.

Grimaldi, M. and Cavalaro, S. (1999) Functional and molecular diversity of PACAP/VIP receptors in cortical neurons and type I astrocytes. Eur. J. Neurosci. 11: 2767-2772. 
Gross, R.E., Mehler, M.F., Mabie, P.C., Zang, Z., Santschi, L., and Kessler, J.A. (1996) Bone morphogenetic proteins promote astroglial lineage commitment by mammalian subventricular zone progenitor cells. Neuron 17: 595-606.

He, F., Ge, W., Martinowich, K., et al., (2005) A positive autoregulatory loop of JakSTAT signaling controls the onset of astrogliogenesis. Nat. Neurosci. 8: 616625.

Hermanson, O., Jepsen, K., and Rosenfeld, M.G. (2002) N-CoR controls differentiation of neural stem cells into astrocytes. Nature 419: 934-939.

Kang, G., Joseph, J.W., Chepurny, O.G., Monaco, M., Wheeler, M.B., Bos, J.L., Schwede, F., Genieser, H.G., and Holz, G.G. (2003) Epac-selective cAMP analog 8-pCPT-2'-O-Me-cAMP as a stimulus for $\mathrm{Ca}^{2+}$-induced $\mathrm{Ca}^{2+}$ release and exocytosis in pancreatic $\beta$-cells. J. Biol. Chem. 278: 8279-8285.

Koblar, S.A., Turnley, A.M., Classon, B.J., Reid, K.L., Ware, C.B., Cheema, S.S., Murphy, M., and Bartlett, P.F. (1998) Neural precursor differentiation into astrocytes requires signaling through the leukemia inhibitory factor receptor. Proc. Natl. Acad. Sci. USA 95: 3178-3181.

Krohn, K., Rozovsky, I., Wals, P., Teter, B., Anderson, C.P., and Finch, C.E. (1999) Glial fibrillary acidic protein transcription responses to transforming growth factor- $\beta 1$ and interleukin- $1 \beta$ are mediated by a nuclear factor-1-like site in the near-upstream promoter. J. Neurochem. 72: 1353-1361.

Lee, M., Lelievre, V., Zhao, P., et al., (2001) Pituitary adenylyl cyclase-activating polypeptide stimulates DNA synthesis but delays maturation of oligodendrocyte progenitors. $J$. Neurosci. 21: 3849-3859. 
Li, Y., Asuri, S., Rebhun, J.F., Castro, A.F., Paranavitana, N.C., and Quilliam, L.A. (2006) The Rap1 guanine nucleotide exchange factor, Epac2, couples cyclic AMP and Ras signals at the plasma membrane. J. Biol. Chem. 281: 2506-2514.

Lu, N., and DiCicco-Bloom, E. (1997) Pituitary adenylate cyclase-activating polypeptide is an autocrine inhibitor of mitosis in cultured cortical precursor cells. Proc. Natl. Acad. Sci. USA 94: 3357-3362.

Lu, N., Zhou, R., and DiCicco-Bloom, E. (1998) Opposing mitogenic regulation by PACAP in sympathetic and cerebral cortical precursors correlates with differential expression of PACAP receptor (PAC1-R) isoforms. J. Neurosci. Res. 53: $651-662$.

Matallanas, D., Arozarena, I., Berciano, M., Aaronson, D.S., Pellicer, A., Lafarga, M., and Crespo, P. (2003) Differences on the inhibitory specificities of H-Ras, KRas, and N-Ras (N17) dominant negative mutants are related to their membrane microlocalization. J. Biol. Chem. 278: 4572-4581.

McManus, M., Chen, L.C., Vallejo, I., and Vallejo, M. (1999) Astroglial differentiation of cortical precursor cells triggered by activation of the cAMP-dependent signaling pathway. J. Neurosci. 19: 9004-9015.

Miller, F.D. and Gauthier, A.S. (2007) Timing is everything: Making neurons versus glia in the developing cortex. Neuron 54: 357-369.

Nakashima, K., Wiese, S., Yanagisawa, M., et al., (1999a) Developmental requirement of gp130 signaling in neuronal survival and astrocyte differentiation. $J$. Neurosci. 19: 5429-5434.

Nakashima, K., Yanagisawa, M., Arakawa, H., Kimura, N., Hisatsune, T., Kawabata, M., Miyazono, K., and Taga, T. (1999b) Synergistic signaling in fetal brain by STAT3-Smad1 complex bridged by p300. Science 284: 479-482. 
Nicot, A. and DiCicco-Bloom, E. (2001) Regulation of neuroblast mitosis is determined by PACAP receptor isoform expression. Proc. Natl. Acad. Sci. USA 98: 47584763.

Nieto, M., Schuurmans, C., Britz, O., and Guillemot, F. (2001) Neural bHLH genes control the neuronal versus glial fate decision in cortical progenitors. Neuron 29: 401-413.

Nishimoto, M., Furuta, A., Aoki, S., Kudo, Y., Miyakawa, H., and Wada, K. (2007) $\mathrm{PACAP} / \mathrm{PACl}$ autocrine system promotes proliferation and astrogenesis in neural progenitor cells. Glia 55: 317-327.

Obara, Y., Horgan, A., and Stork, P.J.S. (2007) The requirement of Ras and Rap1 for the activation of ERKs by cAMP, PACAP, and $\mathrm{KCl}$ in cerebellar granule cells. J. Neurochem. 101: 470-482.

Ochiai, W., Yanagisawa, M., Takizawa, T., Nakashima, K., and Taga, T. (2001) Astrocyte differentiation of fetal neuroepithelial cells involving cardiotrophin-1induced activation of STAT3. Cytokine 14: 264-271.

Pak, Y., Pham, N., and Rotin, D. (2002) Direct binding of the $\beta 1$ adrenergic receptor to the cyclic AMP-dependent guanine nucleotide exchange factor CNrasGEF leads to Ras activation. Mol. Cell. Biol. 22: 7942-7952.

Park, J.K., Williams, B.P., Alberta, J.A., and Stiles, C.D. (1999) Bipotent cortical progenitor cells process conflicting cues for neurons and glia in a hierarchical manner. J. Neurosci. 19: 10383-10389.

Pham, N., Cheglakov, I., Koch, C.A., de Hoog, C.L., Moran, M.F., and Rotin, D. (2000) The guanine nucleotide exchange factor CNrasGEF activates Ras in response to cAMP and cGMP. Curr. Biol. 10: 555-558. 
Pincas, H., Laverriere, J.N., and Counis, R. (2001) Pituitary adenylate cyclaseactivating polypeptide and cyclic adenosine $3^{\prime}, 5^{\prime}$-monophosphate stimulate the promoter activity of the rat gonadotropin-releasing hormone receptor gene via a bipartite response element in gonadotrope-derived cells. J. Biol. Chem. 276: 23562-23571.

Qian, X., Davis, A.A., Goderie, S.K., and Temple, S. (1997) FGF2 concentration regulates the generation of neurons and glia from multipotent cortical stem cells. Neuron 18: 81-93.

Qian, X., Shen, Q., Goderie, S.K., He, W., Capela, A., Davis, A.A., and Temple, S. (2000) Timing of CNS cell generation: A programmed sequence of neuron and glial cell production from isolated murine cortical stem cells. Neuron 28: 69-80.

Rajan, P. and McKay, R.D.G. (1998) Multiple routes to astrocytic differentiation in the CNS. J. Neurosci. 18: 3620-3629.

Raponi, E., Agenes, F., Delphin, C., Assard, N., Baudier, J., Legraverend, C., Deloulme, J.C. (2007) S100B expression defines a state in which GFAP-expressing cells lose their neural stem cell potential and acquire a more mature developmental stage. Glia 55: 165-177.

Rehmann, H., Schwede, F., Dosjeland, S.O., Wittinghofer, A., and Bos, J.L. (2003) Ligand-mediated activation of the cAMP-responsive guanine nucleotide exchange factor Epac. J. Biol. Chem. 278: 38548-38556.

Romano, D., Magalon, K., Ciampini, A., Talet, C., Enjalbert, A., and Gerard, C. (2003) Differential involvement of the Ras and Rap1 small GTPases in vasoactive intestinal and pituitary adenylyl cyclase activating polypeptides control of the prolactin gene. J. Biol. Chem. 278: 51386-51394. 
Sauvageot, C.M. and Stiles, C.D. (2002) Molecular mechanisms controlling cortical gliogenesis. Curr. Opin. Neurobiol. 12: 244-249.

Schmitt, J.M. and Stork, P.J.S. (2001) Cyclic AMP-mediated inhibition of cell growth requires the small G protein rap1. Mol. Cell. Biol. 21: 3671-3683.

Song, M.R., and Ghosh, A. (2004) FGF2-induced chromatin remodeling regulates CNTF-mediated gene expression and astrocyte differentiation. Nat. Neurosci. 7: $229-235$.

Spengler, D., Waeber, C., Pantaloni, C., Florian, H., Bockaert, J., Seeburg, P.H., and Journot, L. (1993) Differential signal transduction by five splice variants of the PACAP receptor. Nature 365: 170-175.

Ster, J., De Bock, F., Guérineau, N.C., Janossy, A., Barrêre-Lemaire, S., Bos, J.L., Bockaert, J., and Fagni, L. (2007) Exchange protein activated by cAMP (Epac) mediates cAMP activation of p38 MAPK and modulation of $\mathrm{Ca}^{2+}$-dependent $\mathrm{K}^{+}$ channels in cerebellar neurons. Proc. Natl. Acad. Sci. USA 104: 2519-2524.

Stork, P.J.S. and Schmitt, J.M. (2002) Crosstalk between cAMP and MAP kinase signaling in the regulation of cell proliferation. Trends Cell Biol. 12: 258-266.

Suh, J., Lu, N., Nicot, A., Tatsuno, I., and DiCicco-Bloom, E. (2001) PACAP is an antimitogenic signal in developing cerebral cortex. Nat. Neurosci. 4: 123-124.

Sun, Y., Nadal-Vicens, M., Misono, S., Lin, M.Z., Zubiaga, A., Hua, X., Fan, G., and Greenberg, M.E. (2001) Neurogenin promotes neurogenesis and inhibits glial differentiation by independent mechanisms. Cell 104: 365-376.

Takizawa, T., Nakashima, K., Namihira, M., Ochiai, W., Uemura, A., Yanagisawa, M., Fujita, N., Nakao, M., and Taga, T. (2001) DNA methylation is a critical cellintrinsic determinant of astrocyte differentiation in the fetal brain. Dev. Cell 1: $749-758$ 
Taylor, S.J. and Shalloway, D. (1996) Cell cycle-dependent activation of Ras. Curr. Biol. 6: 1621-1627.

Vallejo, I. and Vallejo, M. (2002) Pituitary adenylate cyclase-activating polypeptide induces astrocyte differentiation of precursor cells from developing cerebral cortex. Mol. Cell. Neurosci. 21: 671-683.

Van Haastert, P.J., Van Driel, R., Jastorff, B., Baraniak, J., Stec, W.J., and De Wit, R.J. (1984) Competitive cAMP antagonists for cAMP-receptor proteins. J. Biol. Chem. 259: 10020-10024.

Viti, J., Feathers, A., Phillips, J., and Lillien, L. (2003) Epidermal growth factor receptors control competence to interpret leukemia inhibitory factor as an astrocyte inducer in developing cortex. J. Neurosci. 23: 3385-3393.

Vossler, M.R., Yao, H., York, R., Pan, M.G., Rim, C.S., and Stork, P.J.S. (1997) cAMP activates MAP kinase and Elk-1 through a B-Raf- and Rap1-Dependent pathway. Cell 89: 73-82.

Zwartkruis, F.J., Wolthuis, R.M., Nabben, N.M., Franke, B., and Bos, J.L. (1998) Extracellular signal-regulated activation of Rap1 fails to interfere in Ras effector signaling. EMBO J. 17: 5905-5912. 


\section{FIGURE LEGENDS}

Figure 1. PACAP triggers astrocyte differentiation from cortical precursor cells. (A) Control cells growing in the presence of bFGF ( $20 \mathrm{ng} / \mathrm{ml})$ express the neural precursor marker nestin (green) but not the astroglial markers GFAP or S100 $\beta$, nor the neuronal marker Tuj1. Rabbit polyclonal anti-Nestin antiserum was coincubated with either antiGFAP, anti-S100 $\beta$, or anti-Tuj1 monoclonal antibodies. (B) Cells exposed to PACAP $(100 \mathrm{nM})$ express the astroglial markers GFAP (red) and S100 $\beta$ (green), but not nestin or the neuronal marker Tuj1. A rabbit polyclonal anti-GFAP antiserum was coincubated with the anti-S100 $\beta$ monoclonal antibody. (C) Differentiation of neurons from cortical precursor cells exposed to BDNF $(50 \mathrm{ng} / \mathrm{ml})$. Note that in most cells nestin expression (green) is downregulated. Cells showing initiation of neuronal differentiation indicated by the presence of Tuj1 (red) do not express nestin. Examples of these young neurons are indicated by arrowheads. Cells with more advanced degree of differentiation showing dendritic trees typical of fully differentiated neurons are observed. The right panel depicts a higher magnification field. Scale bar corresponds to $50 \mu \mathrm{m}$. In all cases cell nuclei have been counterstained with Hoechst 3342 (blue).

Figure 2. Activation of PKA by PACAP is not involved in stimulation of GFAP expression during astrocyte differentiation. (A and B) Relative levels of luciferase activity elicited in primary cortical precursor cells transfected with the reporter plasmid GFAP-A7Luc. Cells were left untreated (-), or were treated with PACAP (100 nM), 8Br-AMP $(1 \mathrm{mM}), \mathrm{H} 89(10 \mu \mathrm{M})$ or a combination of H89 and PACAP. In this case, PACAP was added 15 minutes after the addition of H89. (C) Western immunoblot showing phosphorylation of CREB by exposure to PACAP (100 nM) for the indicated periods of time (upper panel). A specific anti-phospho-CREB antiserum was used. The 
use of an antiserum that does not discriminate between CREB and phospho-CREB (bottom panel) indicates that the total levels of CREB are not affected by exposure to PACAP. (D) Western immunoblot carried out with an anti-phospho-CREB antiserum showing inhibition of PACAP-induced CREB phosphorylation in the presence of the PKA inhibitor H89 $(10 \mu \mathrm{M})$. Primary cortical cells were exposed to PACAP (100 nM) for 5 minutes, and $\mathrm{H} 89(10 \mu \mathrm{M})$ was added 15 minutes before PACAP. Total CREB immunoreactivity was used as a control to monitor even loading of samples. (E) Western immunoblot showing expression of GFAP in extracts of primary cortical cells treated with PACAP $(100 \mathrm{nM})$, in the absence or presence of H89 $(10 \mu \mathrm{M})$ administered 15 minutes earlier. Cells were exposed to PACAP for two hours and were harvested two days after the onset of treatment. Actin immunoreactivity was used as a control to monitor even loading of samples. (F) Immunocytochemical staining of GFAP in primary cortical cells treated with PACAP $(100 \mathrm{nM})$, in the absence or presence of $\mathrm{H} 89$ $(10 \mu \mathrm{M})$ administered 15 minutes earlier. Cells were exposed to PACAP for two hours and were processed for immunocytochemistry two days after the onset of treatment. Note that the presence of the PKA inhibitor H89 does not prevent GFAP expression (E) or astrocyte differentiation $(\mathrm{F})$.

Figure 3. Involvement of the activation of Rap1 in PACAP-induced stimulation of the GFAP promoter. (A) GST pull down assay showing activation of Rap1 (Rap1-GTP) in response to treatment of primary cortical precursor cells either with PACAP (100 nM) for the indicated periods of time (minutes), or with the cAMP analog 8CPT-2-O-MecAMP (8CPT-cAMP), a specific agonist for the activation of Epac. Cells were exposed to 8CPT-2-O-Me-cAMP $(100 \mu \mathrm{M})$ for 15 minutes. (B) Relative luciferase activities elicited in primary cortical precursor cells cotransfected with the reporter plasmid 
GFAP-A7Luc and with the indicated amounts $(\mu \mathrm{g})$ of an expression vector encoding Rap1N17, a dominant negative mutant of Rap1. Cells were left untreated (white columns), or treated (black columns) with PACAP $(100 \mathrm{nM}) .{ }^{*} p<0.01$ relative to values obtained in PACAP-treated cells in the absence of Rap1N17 (Student's t-test). (C) A similar experiment to the one indicated in (B), but treating cells with CNTF (30 ng/ml) instead of PACAP.

Figure 4. Stimulation of Epac is not sufficient to induce GFAP gene expression during astrocyte differentiation. (A) Relative levels of luciferase activity elicited in primary cortical precursor cells transfected with the reporter plasmid GFAP-A7Luc. Cells were left untreated (-), or were treated with PACAP (100 nM), 8Br-cAMP (1 mM), or 8CPT2-O-Me-cAMP (8CPT-cAMP, 10 or $100 \mu \mathrm{M})$. (B) Western immunoblots carried out with extracts of primary cortical precursor cells showing induction of GFAP expression in cells treated with PACAP $(100 \mathrm{nM})$ or $8 \mathrm{Br}-\mathrm{cAMP}(1 \mathrm{mM})$, but not in those treated with 8CPT-2-O-Me-cAMP (8CPT-cAMP, $100 \mu \mathrm{M})$. (C) Immunocytochemical staining of GFAP in primary cortical precursor cells induced to differentiate to astrocytes by treatment with PACAP (100 nM). Note that astrocyte differentiation was not induced in cells treated with 8CPT-2-O-Me-cAMP (8CPT-cAMP, $100 \mu \mathrm{M})$.

Figure 5. Involvement of the activation of Ras in PACAP-induced stimulation of the GFAP promoter. (A) GST pull down assay showing activation of Ras (Ras-GTP) in response to treatment of primary cortical precursor cells with PACAP $(100 \mathrm{nM})$ for the indicated periods of time. (B) Relative luciferase activities elicited in primary cortical precursor cells cotransfected with the reporter plasmid GFAP-A7Luc and with the indicated amounts $(\mu \mathrm{g})$ of an expression vector encoding RasN17, a dominant negative 
mutant of Ras. Cells were left untreated (white columns), or were treated (black columns) with PACAP $(100 \mathrm{nM}) . * p=0.024$ and ${ }^{* *} p<0.02$, relative to values obtained in PACAP-treated cells in the absence of RasN17 (Student's t-test). (C) A similar experiment to the one indicated in (B), but treating cells with CNTF (30 ng/ml) instead of PACAP. (D) Relative luciferase activities elicited in primary cortical precursor cells cotransfected with the reporter plasmid GFAP-A7Luc and with the indicated amounts $(\mu \mathrm{g})$ of an expression vector encoding RasV12, a constitutively active mutant of Ras. For comparison, the luciferase activity of cells transfected only with GFAP-A7Luc and treated with PACAP $(100 \mathrm{nM})$ is shown.

Figure 6. Involvement of cAMP on the PACAP-induced activation of Ras. (A) GST pull down assay showing activation of Ras (Ras-GTP) in response to treatment of primary cortical precursor cells with PACAP $(100 \mathrm{nM})$ for 5 minutes. Note that PACAP failed to activate Ras in the presence of the cAMP antagonist Rp-cAMPS (10 $\mu \mathrm{M})$, which was administered 10 minutes before PACAP. (B) Relative luciferase activities elicited in primary cortical precursor cells cotransfected with the reporter plasmid GFAP-A7Luc and with the indicated amounts $(\mu \mathrm{g})$ of an expression vector encoding RasN17, a dominant negative mutant of Ras. Cells were left untreated (white columns), or were treated (black columns) with the cAMP analog 8Br-cAMP $(1 \mathrm{mM}) .{ }^{*} p<0.005$ relative to values obtained in $8 \mathrm{Br}$-cAMP-treated cells in the absence of RasN17 (Student's t-test)

Figure 7. (A) Relative luciferase activities elicited in primary cortical precursor cells cotransfected with the reporter plasmid GFAP-A7Luc and with expression vectors encoding Rap1N17 $(1 \mu \mathrm{g})$ or RasN17 $(0.5 \mu \mathrm{g})$. Cells were left untreated (white 
columns), or were treated (black columns) with the PACAP (100 nM). Note that when both dominant negative inhibitors are present at the same time the effect of PACAP on the GFAP promoter activity is almost completely inhibited. (B) A similar experiment to the one indicated in (B), but treating cells with CNTF (30 ng/ml) instead of PACAP. (C) Western immunoblot showing endogenous GFAP expression in cells transfected with siRNA for Rap1 and Ras as indicated on top. Note that the presence of siRNA for both Rap1 and Ras at the same time specifically prevents stimulation of GFAP expression by PACAP but not by CNTF. Actin immunoreactivity was used as a control to monitor even loading of samples. (D) Relative luciferase activities elicited in primary cortical precursor cells cotransfected with the reporter plasmid GFAP-A7Luc and with the indicated amounts $(\mu \mathrm{g})$ of an expression vector encoding RasV12. Some cells were treated with 8CPT-2-O-Me-cAMP (8CPT-cAMP, $100 \mu \mathrm{M})$. For comparison, the first two bars to the left depict the increase in luciferase activity observed in cells transfected only with GFAP-A7Luc and treated with PACAP $(100 \mathrm{nM}) .{ }^{*} p<0.05$, relative to values obtained in 8CPT-2-O-Me-cAMP-treated cells in the absence of RasV12 (Student's ttest). 


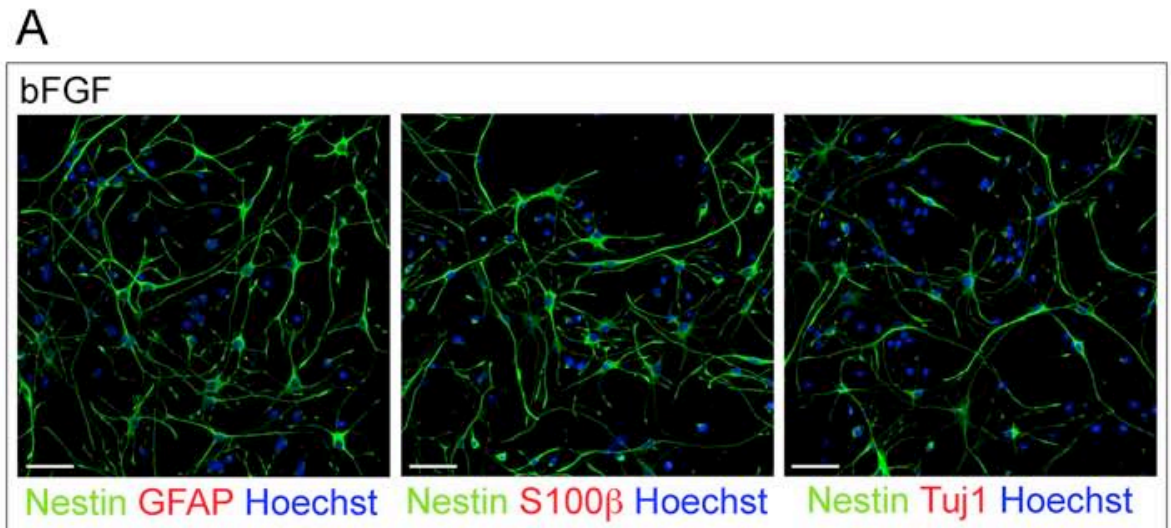

B

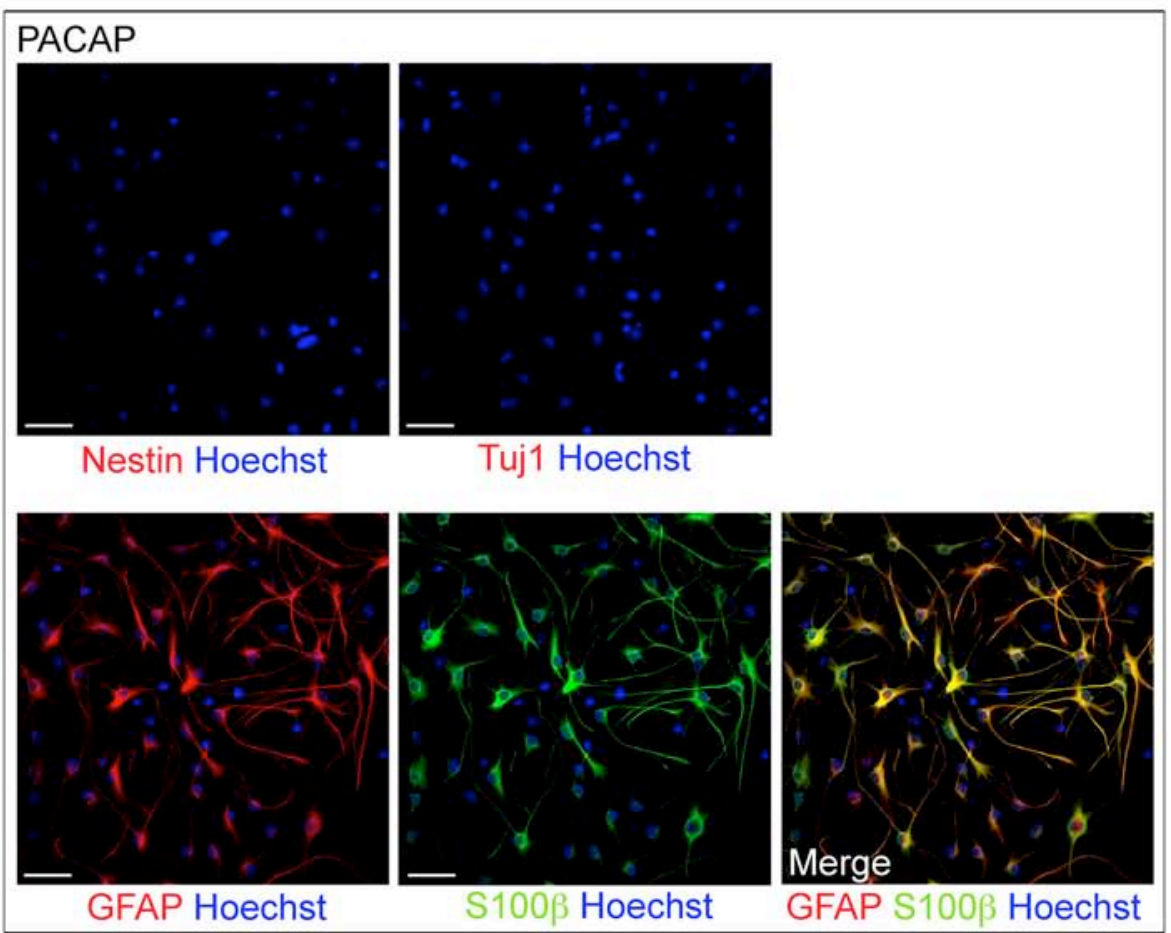

C

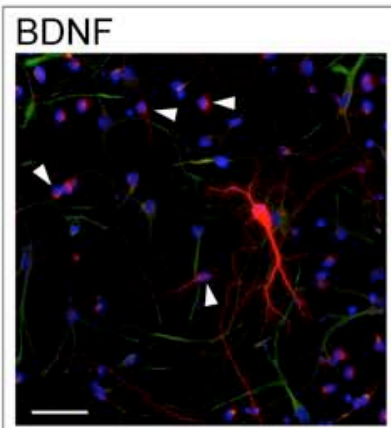

Nestin Tuj1 Hoechst

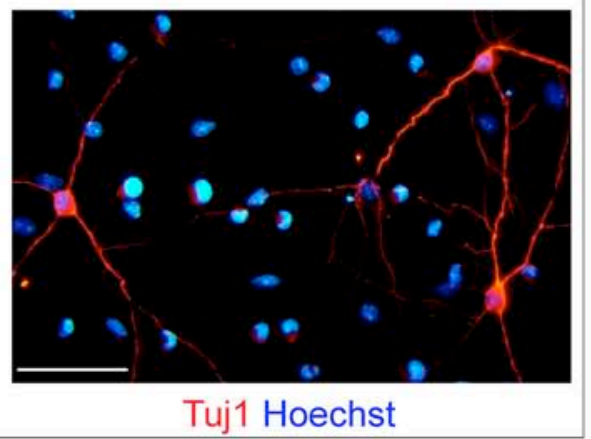

Figure 1 

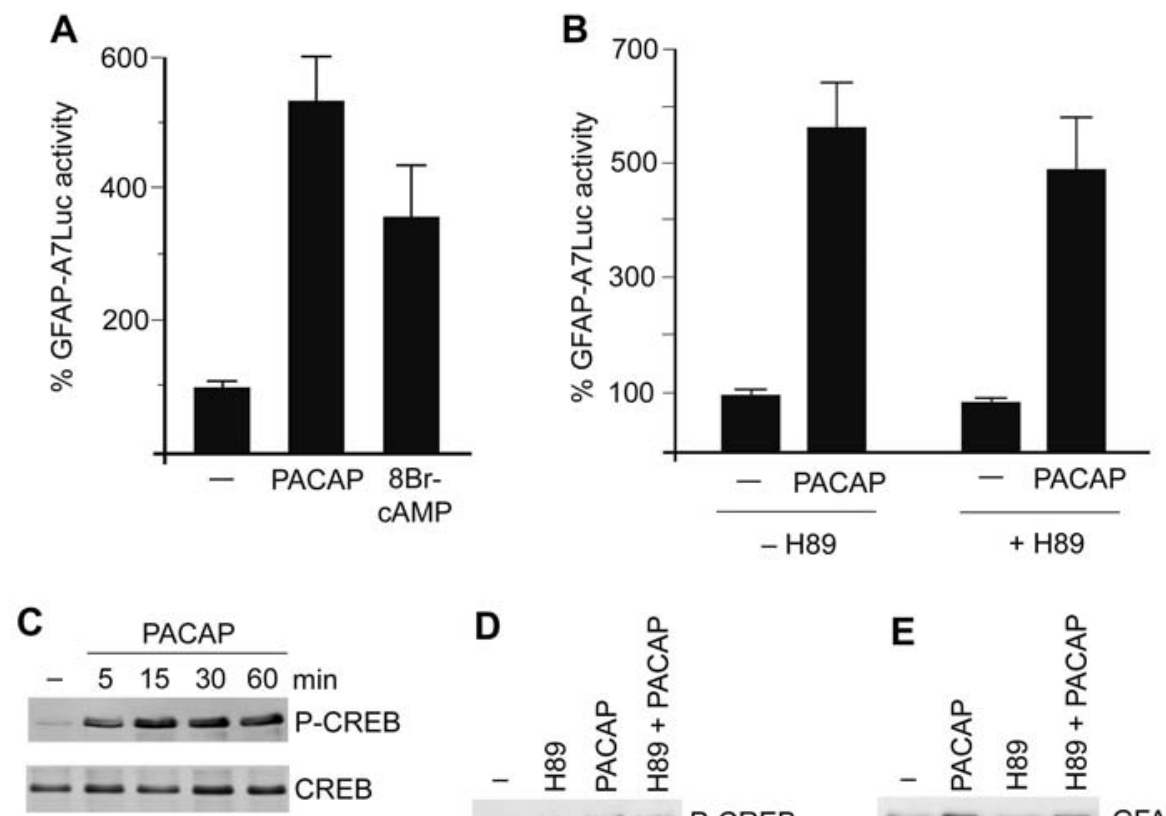

D
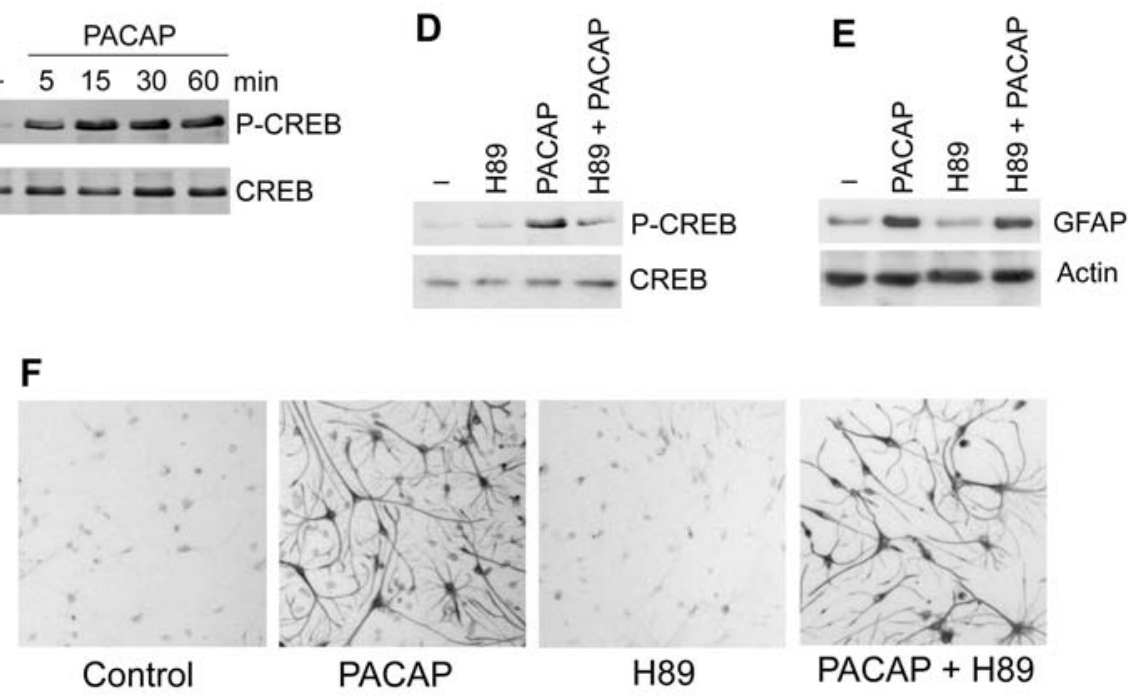

Figure 2 

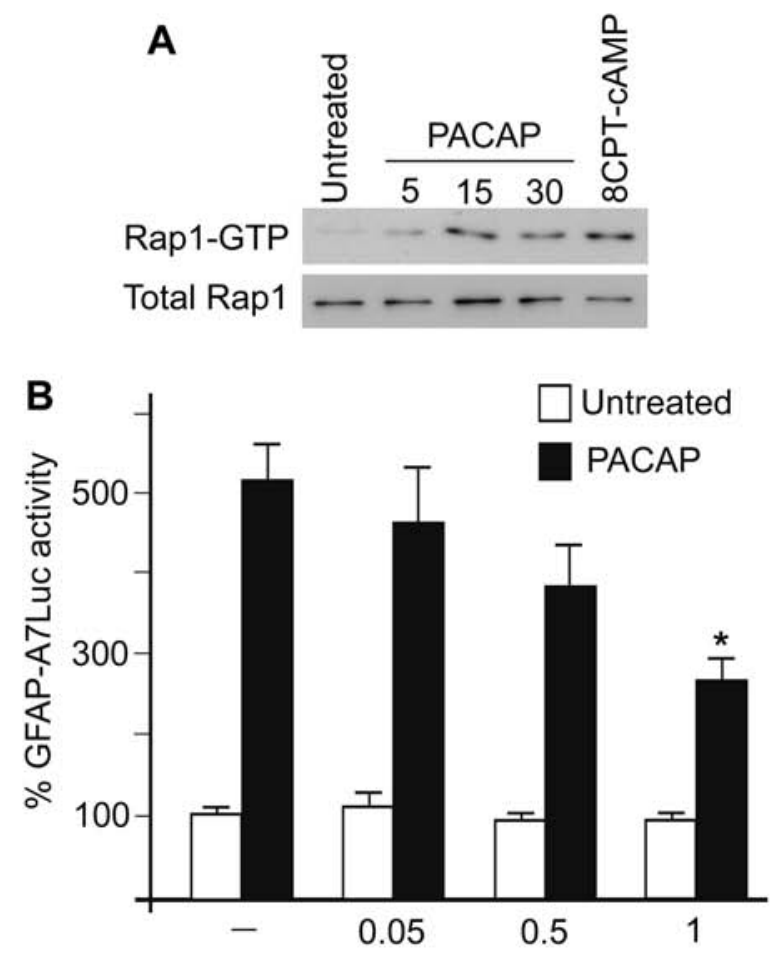

Rap1N17

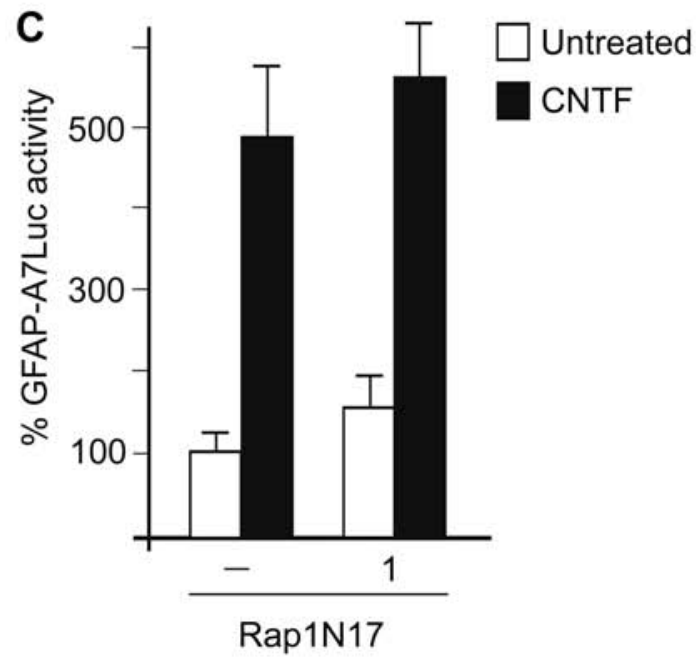

Figure 3 

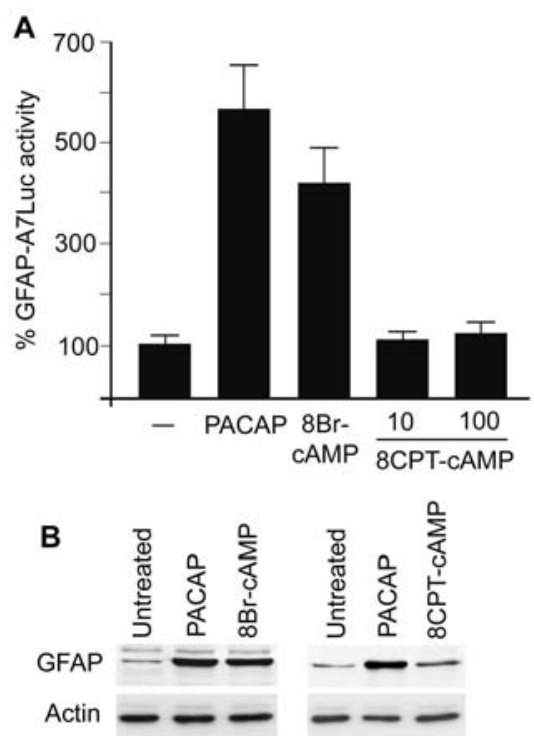

C

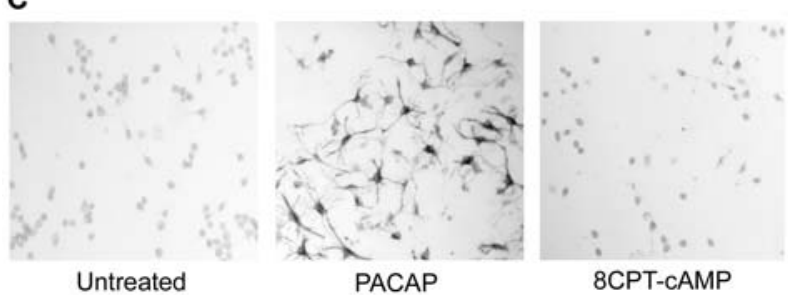

Figure4

A

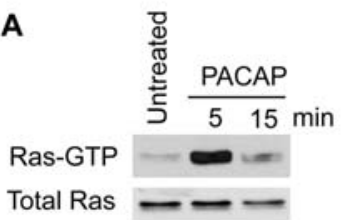

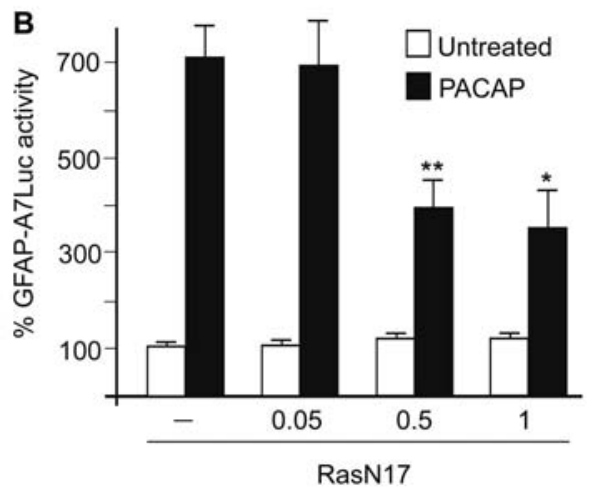

D

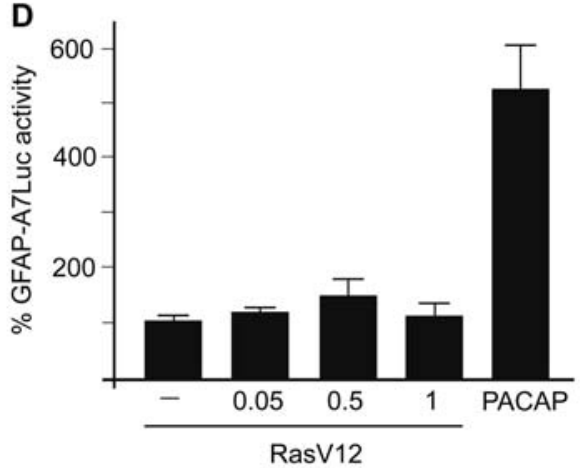

Figure 5 


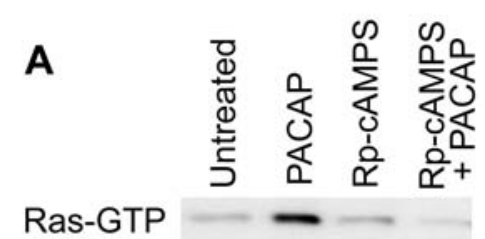

Total Ras $-\cdots$

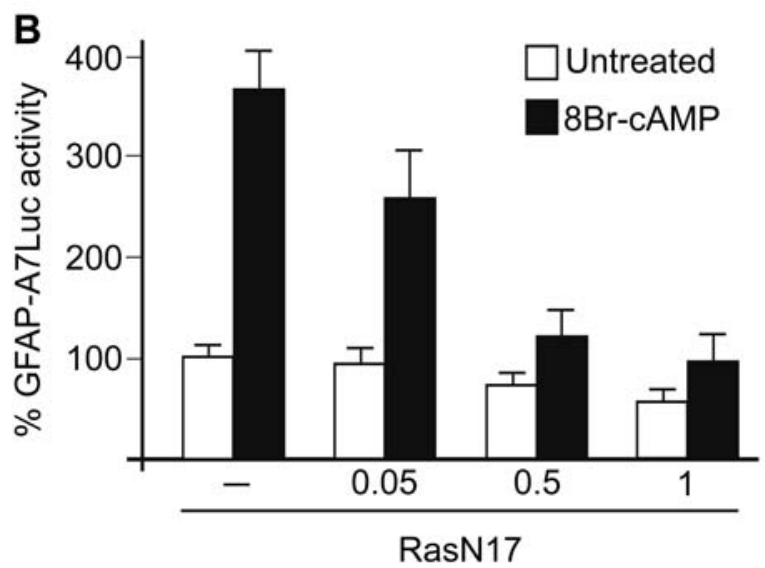

Figure 6
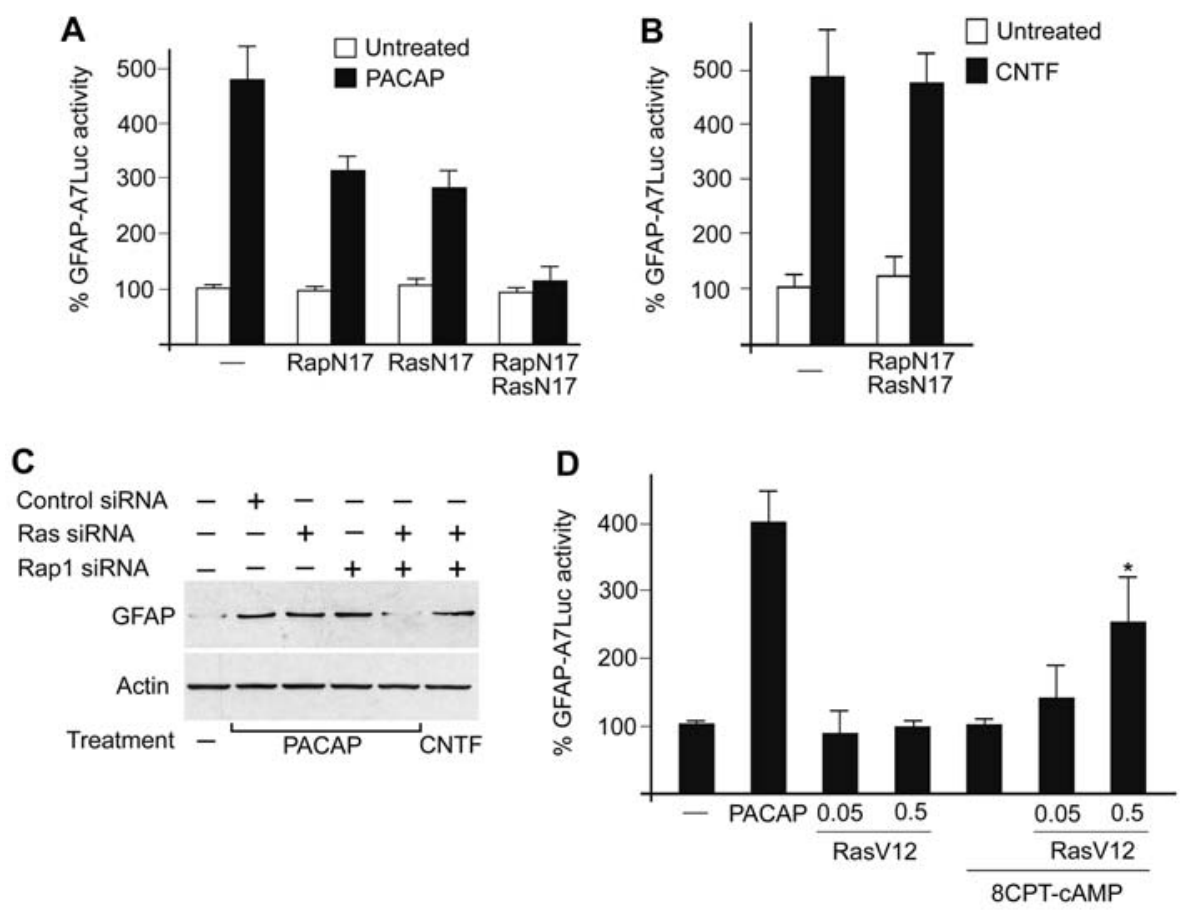

Figure 7 